\section{BJSM leadership: honouring a legacy and a look to the future}

\author{
Jonathan A Drezner
}

$B J S M$ is more than a scientific journal. It is the international home for sports and exercise medicine (SEM) research, education, and scholarship, and strives to support and serve the broad SEM community. The BJSM community embodies SEM clinicians and researchers around the globe who are dedicated to improving patient care, advancing the scientific foundation of our discipline and open to constructive dialogue and exchange. The journal and its multimedia platform have emerged as the premier home for presenting and disseminating the best in SEM research. As the BJSM 'family' continues to grow, so does our opportunity and responsibility to impact the patients under our care and the communities in which we live.

It is my great honour and humble privilege to become the next Editor-in-Chief of this prestigious journal and an ambassador for this respected community. Of course, our success sits on the broad shoulders of the leaders that have come before. It is thus with massive appreciation and gratitude we must thank Professor Karim Khan (BJSM Editor-inChief, 2008-2020) whose dedication and vision have both elevated the journal and reshaped how we engage in new science and discovery.

\section{HONOURING A LEGACY}

For so many of us, Karim has been both a mentor and a friend. From the first time we met (2001), I was taken by his genuine interest to understand who I was and what my interests were. As we sat for dinner on the streets of Miami, he leaned in with attention, taking hand-written notes on the names of my family members as well as my research interests. Karim is living proof that true mentorship supports the whole person, and not just the goal of scholarly achievement. I am grateful for his support and guidance over many years, and the many connections he has facilitated within the international SEM

Sports Medicine Center, University of Washington, Seattle, Washington, USA

Correspondence to Dr Jonathan A Drezner, Stadium Sports Medicine Center, University of Washington, Seattle, WA 98115, USA; jdrezner@uw.edu community that share a rich enthusiasm for new learning and collaboration.

Karim's accomplishments as Editor-inChief, and his personal commitment to help others, represent a legacy that has driven our field to new heights. BJSM carries an impact factor of 12.68 (\#1 in Sports Medicine/Sports Science) and has $>75000$ Twitter followers! Although it will be difficult to fill his shoes, we would be remiss if we did not honour his legacy and build on the rising achievements of the journal.

\section{SUCCESSFUL LEADERSHIP REQUIRES A GREAT TEAM}

We are also indebted to BJSM EditorsProfessors Babette Pluim, Kay Crossley and Emmanuel Stamatakis-for their many years of service and contributions steering BJSM towards more rigorous science, stronger methodology and greater clinical impact, while maintaining a keen eye on the evaluation and selection of submitted papers. While other important endeavours are pulling them from their current roles within BJSM, I am certain we will seek their guidance and call on on their expertise to further direct BJSM. I am also thankful for the leadership of Professor Lars Engebretsen and our continued partnership with the IOC embracing a shared commitment towards Injury Prevention and Health Promotion.

As I assess the BJSM landscape, I am reminded of the first rule of leadership ... surround yourself with great people! I am delighted to announce our core Editor team beginning in 2021-Dr's Joanne Kemp (La Trobe University, Australia), Jane Thornton (Western University, Canada) and Jon Patricios (Wits University, South Africa). Besides our commitment to SEM, we share a common vision for a healthier world. A world where exercise and fitness are the foundation to physical and mental health; where the privilege and platform of SEM in elite sport is applied with equal passion to youth, disadvantaged and under-represented populations; where injury prevention programmes are as common in schools as they are in premier sports academies; and where prevention of sudden death is both prioritised and realised at all levels of sport, independent of resources and country.

BJSM has a talented Editorial Board, and I am excited about our direction and the opportunities ahead. As a team, we will continue to confront important issues on diversity, inclusion and equity, and work to cultivate new pathways for under-represented groups within science and publishing.

\section{OUR MISSION AND VISION}

BJSM aims to advance the scientific foundation of SEM, expand the evidence-base that guides clinical decision-making, and facilitate knowledge translation which implements research into practice and policy. As Editor-in-Chief, the integrity of our review process is paramount. It is my foremost responsibility to oversee the quality and selection of scientific content by ensuring a fair, timely, and thorough review process that maintains the highest standards of academic integrity. $B J S M$ is fortunate to attract the finest in SEM research and receives $>1700$ manuscript submissions per year! However, limited space dictates an acceptance rate of $<10 \%$, and many high-quality papers cannot be accepted. Editorial decisions and article selection are based on their content, methodology, overall quality, priority and impact on clinical practice. Importantly, author status is not considered. As a prospective author or reviewer, this $B M J$ adage is helpful to remember: 'Is it new? Is it true? Does it change what we do?'

BJSM will promote cutting-edge and thought-leading research that advances our field and creatively use our multimedia portal to reach current and new BJSM readers. BJSM will maintain its emphasis on high quality original investigations with strong methodology, systematic reviews and meta-analyses, and evidence-driven consensus statements. Priority domains include concussion, injury prevention, mental health, muscle and joint injury, physical activity and exercise medicine, social determinants and health equity relevant to SEM, sports cardiology and sudden death prevention, and tendinopathy. I look forward to developing innovative ways to make our papers and key clinical information more accessible to our 25 BJSM Clinical Societies and the SEM community at-large.

\section{LOOKING AHEAD: LIFT, LEAD AND INSPIRE}

Finally, we must pause and recognise that 2020 has been a year of 


\section{Editorial}

crisis. The COVID-19 pandemic has created extraordinary public health and economic crises; climate change has led to extreme weather events and devastating fires on different continents; and racial injustice and systemic racism continue to plague our society. The complete shut-down of sports early in the COVID-19 pandemic and incomplete lifting of restrictions thus far have shuttered youth sports and public venues for recreation, creating additional public health crises of physical inactivity and mental distress. New research must emerge to guide a safe return to sports and exercise for all persons in all locations. To this regard, I am proud of the strong collaboration
I have witnessed among medical professionals working to find solutions to these new challenges.

As gatekeepers and promoters of health and exercise, BJSM will support you to make better, safer, and more informed clinical decisions. The BJSM community is filled with compassionate individuals and thoughtful leaders, and together we can lift, lead and inspire efforts towards a 'healthier world'. BJSM is committed to spotlight colleagues who are simply making a difference in their communities. As I embark on this journey with you, I do so with great humility and enthusiasm. \#StrongerTogether

Twitter Jonathan A Drezner @DreznerJon
Funding The author has not declared a specific grant for this research from any funding agency in the public, commercial or not-for-profit sectors.

Competing interests None declared.

Patient consent for publication Not required.

Provenance and peer review Commissioned; internally peer reviewed.

(c) Author(s) (or their employer(s)) 2021. No commercial re-use. See rights and permissions. Published by BMJ.

\section{Check for updates}

To cite Drezner JA. Br J Sports Med 2021;55:1-5.

Accepted 2 November 2020

Br J Sports Med 2021;55:1-5

doi:10.1136/bjsports-2020-103649

\section{ORCID iD}

Jonathan A Drezner http://orcid.org/0000-0003-35199120 